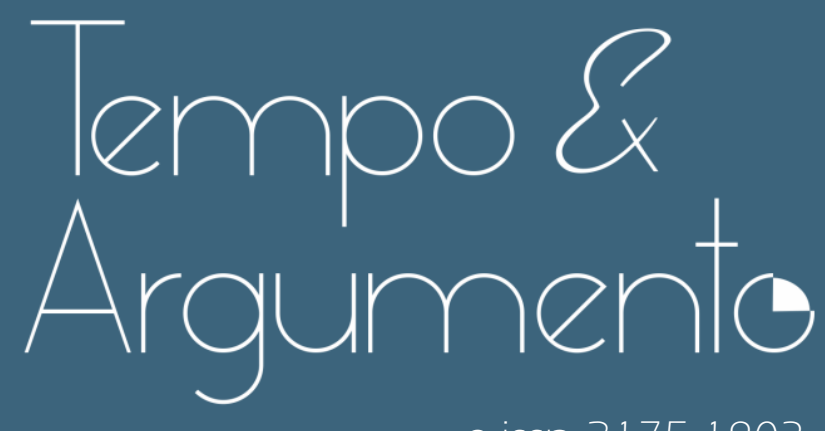

e-issn 2175-1803

História do Tempo Presente, História Pública e a divulgação científica da história

\title{
Entrevista com
}

\& Bruno Leal Pastor de Carvalho

Doutor em História Social pela Universidade Federal do Rio de Janeiro (UFRJ).

Professor na Universidade de Brasília (UnB).

Brasilia, DF - BRASIL

lattes.cnpq.br/5008387707815296

brunoleal2003@gmail.com

(D) orcid.org/0000-0002-1 158-5708

Entrevista concedida ̀̀

- Luana Borges Lemes

Doutoranda em História na Universidade do Estado de Santa Catarina (UDESC).

Florianópolis, SC - BRASIL

lattes.cnpq.br/5826805693736770

luborgeslemes@gmail.com

(D) orcid.org/0000-0003-3482-1993

Para citar este texto:

CARVALHO, Bruno Leal Pastor de. História do Tempo Presente, História Pública e a divulgação científica da história [Entrevista realizada em abril de 2020]. Revista

Tempo e Argumento, Florianópolis, v. 12, n. 29, e0402. jan/abr. 2020.

Entrevistadora: Luana Borges Lemes

doi dx.doi.org/10.5965/2175180312292020e0402 


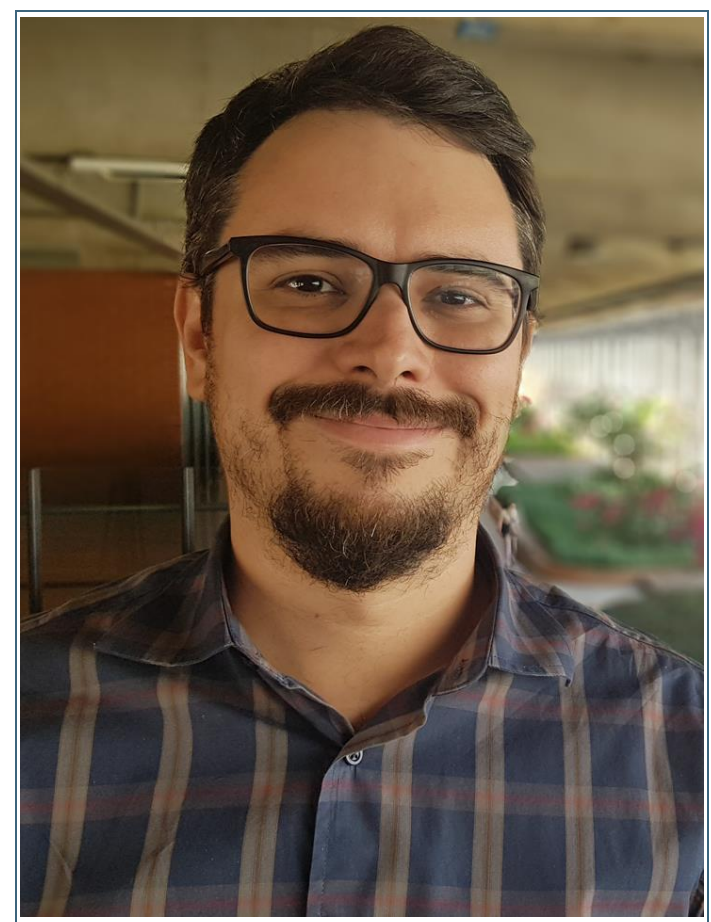

Bruno Leal Pastor de Carvalho é fundador e editor do Café História. É professor adjunto de História Contemporânea do Departamento de História da Universidade de Brasília (UnB). Doutor em História Social pela Universidade Federal do Rio de Janeiro (UFRJ) (2015). Foi professor do Departamento de História da Universidade Federal Fluminense (UFF). Realizou pós-doutorado em História Social na Universidade Federal do Rio de Janeiro. Foi cocoordenador do Núcleo Interdisciplinar de Estudos Judaicos e Árabes da UFRJ, o NIEJ, entre 2011 e 2018. É membro da Rede Brasileira de História Pública e da Associação das Humanidades Digitais. Desenvolve pesquisas sobre História Pública, História digital e divulgação científica, crimes nazistas e justiça no pós-guerra.

Tempo \& Argumento: Na sua trajetória profissional, o Jornalismo e a História "caminharam" juntos. Como é trabalhar nas duas áreas do conhecimento de forma concomitante?

Bruno Leal Pastor de Carvalho: Eu sempre fui apaixonado por esses dois campos profissionais. Quando entrei na faculdade, em 2003, as pessoas sempre me perguntavam se eu estava fazendo um curso para "complementar" o outro. Mas não era nada disso. Eu sempre quis ser jornalista e historiador. Nunca passou pela minha cabeça ter que escolher uma ou outra profissão e jamais achei que uma formação era menor do que a outra a ponto de ser um mero "complemento". Minha identidade profissional sempre foi dupla. E isso não me causa qualquer tipo de crise.

Quando eu estava prestes a me formar percebi que a divulgação de história, através da chave da divulgação científica, era uma excelente forma de articular as minhas duas formações. E deu certo. Atualmente, sou jornalista e historiador no Café História1. A função de editor permite isso. Eu escolho as pautas (com a ajuda do público), penso as

\footnotetext{
Site editado pelo historiador Bruno Leal Universidade de Brasília (UnB) e pela historiadora Ana Paula Tavares - Fundação Getúlio Vargas - Rio de Janeiro (FGV-RJ), disponível em: https://www.cafehistoria.com.br/
} 
abordagens em termos de historiografia, estruturo o texto com a cabeça de um comunicador, faço marketing digital para promover nosso conteúdo, tento dar visibilidade a temas que nem sempre são visíveis no campo da História, corro atrás de notícias, entrevisto pessoas e busco evidenciar o trabalho dos meus pares. Enfim, são habilidades que devo a essa minha dupla formação.

Tempo \& Argumento: Os debates teórico-metodológicos do campo da História Pública influenciaram o seu trabalho em relação à divulgação científica da História?

Bruno Leal Pastor de Carvalho: Quando eu comecei o Café História, as minhas maiores referências metodológicas e teóricas eram a divulgação científica, com a qual eu tivera contato na faculdade de jornalismo, e as chamadas comunidades de práticas (CoP), conceito desenvolvido pelo antropólogo Etienne Wenger para designar reunião de indivíduos de um mesmo campo profissional que, a partir de diferentes saberes especializados, resolvem juntos um problema ou sofisticam um dado processo de trabalho. Em 2008, eu não fazia ideia ainda do que era História Pública. A propósito, pouca gente no Brasil conhecia o conceito de Public History.

Em 2012, eu fui convidado para participar de uma mesa e para ministrar uma oficina no 1o Simpósio Internacional de História Pública na Universidade de São Paulo (USP). Neste evento, tive meu primeiro contato com História Pública e isso me fez ver o meu trabalho com divulgação científica de outra forma. Eu passei a me preocupar mais com o engajamento dos meus leitores, com a questão dos diferentes públicos e com a noção de audiência.

Atualmente, há muita sobreposição entre as propostas da divulgação científica e da história pública no Brasil. E acho que isso é compreensível. A história e as demais ciências humanas, afinal de contas, não costumam ser pensadas por aqui como as "ciências da divulgação científica". Além disso, os historiadores, com algumas e importantes exceções, raramente se ocuparam muito com a difusão do conhecimento historiográfico para o grande público. Ora, quando os historiadores começaram a se ocupar mais profundamente com esse tipo de coisa, há alguns anos, nossa referência não foi a divulgação científica, mas a História Pública, que desde os anos 1970 vinha sendo 
desenvolvida fora do Brasil. Eu não acho que a História Pública teria se desenvolvido tão fortemente e com tanta rapidez por aqui se tivéssemos nos interessado mais por divulgação científica e se a divulgação científica tivesse acolhido mais a história e as demais humanidades. Então, perdemos por um lado, ganhamos por outro.

De qualquer forma, esses dois campos, a despeito das sobreposições, estão entendendo onde e como se diferenciam e, a partir desse entendimento, tem surgido um rico diálogo. A História Pública, por exemplo, tem um lado performático e de engajamento com o público mais aflorado do que a divulgação científica. Assim, nós começamos a olhar para as experiências de uma e de outra e aprendemos com ambas - de forma que uma obsessão em demarcar as diferenças entre as duas, como se fossem competidoras, não me parece fazer muito sentido.

Eu tenho certeza que muitos divulgadores científicos olham para o que nós, historiadores públicos, fazemos e pensam: "caramba, mas nós também fazemos isso e há muito tempo". Da mesma forma que bibliotecários e museólogos também devem pensar. E isso acontece porque a História Pública é antes de tudo um movimento, uma morada para muitos profissionais que lidam com a história enquanto historiografia e ciência. A História Pública é um amálgama. Acho que foi a presença marcante da História Pública, entre nós historiadores, nos últimos anos, que fez muita gente começar a pensar a História como uma das ciências da divulgação científica e em como fazer divulgação científica de história.

Tempo \& Argumento: O que levou o professor a criar o portal de divulgação cientifica Café Historia?

Bruno Leal Pastor de Carvalho: A ideia do Café História começou em meados da minha graduação, mais ou menos em 2005. Era uma época incrível para quem, como eu, é fascinado por tecnologias da comunicação: programas de reality show, popularização da banda larga, transição da televisão analógica para a digital, explosão no número de lan houses, primeiras experiências com o streaming e o surgimento do 3G. Tudo isso era discutido nas disciplinas do meu curso de comunicação. Era algo excitante - a sensação era a de que estávamos vivendo um momento único. 
No curso de história, por outro lado, esse debate era muito tímido, quase inexistente. Em geral, a tecnologia ainda era subestimada. A internet, por exemplo, era vista por muitos de meus colegas como mais um meio de entretenimento do que de possibilidades de transformação da historiografia. Havia bem poucos projetos de divulgação de história na internet e eu me ressentia muito por isso. Uma das perguntas que comecei a me fazer era: como usar todas essas novas ferramentas digitais para conectar os historiadores e dar visibilidade aos seus trabalhos? Na época, tentei responder a essa pergunta criando fóruns na internet, blogs e comunidades no antigo Orkut. Nada deu muito certo. Até que um dia conheci a plataforma Ning, a primeira plataforma na qual o Café História foi hospedado. Ela permitia que qualquer pessoa criasse a sua própria rede social. Na hora entendi que era daquilo que eu precisava para conectar os historiadores uns com os outros e com o público. Levou mais ou menos um mês para concluir a rede e lançá-la na web. E essa tem sido a minha vida na última década.

Tempo \& Argumento: Comente sobre as dinâmicas entre escolha de conteúdos temáticos da História e a otimização de mídias sociais para obter visibilidade do portal.

Bruno Leal Pastor de Carvalho: É uma pergunta muito instigante. Começo falando sobre a questão da escolha de conteúdo. Quando começamos a trabalhar com divulgação científica, rapidamente somos testados quanto às demandas da audiência. A escuta ativa é algo que valorizo e pratico no Café História. Eu escuto os leitores, procuro entender o que eles querem ver no site e como. Porém, nenhum veículo de comunicação deve pautar-se somente de acordo com a demanda do seu público. E é tentador se entregar a ela, pois ela rende cliques, curtidas e compartilhamentos. Mas, quando cedemos totalmente a essa demanda, corremos o grave risco de silenciar questão já muito silenciadas.

Pode parecer um contrassenso do ponto de vista da comunicação, mas acredito que uma das funções de todo editor de divulgação científica é trazer à tona temas que são invisibilizados, sobretudo por causa de preconceitos ou tabus. Um exemplo: sempre que publico algo sobre Segunda Guerra Mundial, o número de acessos ao Café História dispara. Por outro lado, quando publico algo sobre transexualidade, os 
acessos despencam. Se você busca apenas a audiência, o acesso, o compartilhamento, você vai publicar apenas sobre Segunda Guerra Mundial e deixar a questão das comunidades trans para lá. Isso é um enorme problema, pois essa postura faz com que eu contribua para o silenciamento de questões históricas e sociológicas essenciais. Falar sobre elas é uma forma de combater essa invisibilidade. Bourdieu² tem um texto muito interessante no qual fala sobre esse poder do editor. O editor, ele explica, é aquele sujeito que controla uma espécie de portal, aquilo que será conhecido ou não. Quando fazemos divulgação, podemos ser, além de divulgadores, editores de divulgação também. Esse trabalho traz uma enorme responsabilidade, portanto.

Agora, passo para a segunda questão, que é sobre as mídias sociais. Boa parte dos acessos do Café História são provenientes de mecanismos de busca, como o Google, o Yahoo e o Bing. Sem os motores de busca, a "encontrabilidade" de um site é muito difícil. O sonho de qualquer editor de site é obviamente ter o seu projeto aparecendo nas primeiras páginas de busca do Google - há várias pesquisas que mostram que as pessoas dificilmente vão além da terceira página de resultado. Para estar bem posicionado, os editores precisam ter noção de uma técnica chamada Search Engine Optimization (SEO). Essa técnica diz respeito a mais de uma centena de variáveis que o Google (seus algoritmos, na verdade) processa a fim de estabelecer os seus rankings de resultados. Vou dar alguns exemplos de coisas que são fundamentais para a elaboração desses rankings: velocidade do site, peso das imagens, quantidade de itens, frequência de atualizações, uso de palavras-chave, tamanho do texto etc. São realmente centenas de itens, alguns conhecidos e outros não. Para ter um bom SEO, o editor precisa estudar bastante essa área do conhecimento - ciência da computação.

Além dos acessos oriundos dos motores de busca, um site também pode receber acessos se ele se fizer presente nas redes sociais: Facebook, Twitter, Instagram, YouTube etc. Quanto mais ramificado nessas redes for um determinado site, maior é a possibilidade de receber mais visitas. Eu tenho uma dica de ouro nesses casos: se você quiser ter muitos seguidores e engajamentos em suas redes sociais e aumentar o fluxo de visitas para o seu site, poste todos os dias nessas redes, e mais de uma vez, mas não poste qualquer coisa, poste 
conteúdo de qualidade. Isso é fundamental. Os algoritmos são mecanismos alimentados por conteúdos. Então, quanto mais você postar, mais ele vai "gostar de você". Isso traz, claro, uma série de problemas de ordem ética e política. Por exemplo: o que fazer quando o apetite do algoritmo é tão grande a ponto de nos tornar reféns de seus critérios? Ou ainda: em que medida, ao alimentar esse algoritmo, nós contribuímos para agravar distorções no consumo e na busca de informações e conhecimento. Embora não tenhamos tempo e espaço aqui para entrar em detalhes sobre esses riscos, certamente é algo que devemos considerar. Mas a questão básica quando falamos de estratégias em mídias sociais é essa: frequência e periodicidade. 0 problema é que isso é muito difícil, pois demanda um comprometimento que nem todos são capazes de ter.

Atualmente, o Facebook fez uma mudança muito ruim em seus algoritmos. Por mais que um editor publique bons conteúdos e de forma bem ritmada, ele não vai crescer. O Facebook tem privilegiado e premiado os produtores de conteúdos que pagam para impulsionar seus posts. A coisa funciona mais ou menos assim: você tem 500 mil seguidores no Facebook. No entanto, quando você posta alguma coisa, esse conteúdo vai ser exibido para uma fração muito pequena desses 500 mil, digamos uns 2 mil. Se o conteúdo em seus primeiros minutos de exibição receber muitas curtidas, comentários e compartilhamentos, o Facebook começa a entregá-lo para mais dos seus seguidores. Desde 2014, porém, o Facebook criou uma forma de "queimar etapas": você pode exibir seu conteúdo, seja lá qual for a qualidade dele, se você pagar. É isso o que ele chama de impulsionamento. Trata-se de uma tragédia para produtores de conteúdo que não dispõem de muitos recursos financeiros. Mesmo empresas grandes têm se incomodado com essa política. O jornal Folha de São Paulo, recentemente, deixou de atualizar seu perfil no Facebook por causa dela. O Café História ainda não fez isso, isso é, não deixamos a rede, mas tem deixado cada vez mais de lado o Facebook para se dedicar a outras redes, caso do Instagram - que pertence ao Facebook, mas que ainda tem algoritmos menos injustos. 
Tempo \& Argumento: Quais os impactos do portal de divulgação científica Café Historia para a área da História (no âmbito da pesquisa e do ensino)? Qual é o público que acessa o portal?

Bruno Leal Pastor de Carvalho: Até onde eu sei, o Café História é o portal de divulgação científica de história em língua portuguesa mais antigo da internet. Mas, o Café História tem não só antiguidade; ele tem também periodicidade, conteúdos produzidos por historiadores profissionais, edição centralizada e presença em diversas redes sociais. Não conheço nenhum outro projeto do gênero que reúna todos esses atributos. Nem em língua estrangeira. É possível que exista, mas eu não conheço. Acho que é isso que tem feito dele uma referência para estudantes, professores e pessoas com diversas formações, mas que têm interesse em história.

Nos últimos dois anos, nós estamos tentando mapear os impactos sociais e acadêmicos dos conteúdos do Café História. Quanto aos impactos sociais, usamos uma ferramenta chamada Google Analytics, que nos fornece uma série de relatórios de acesso ao site. Graças a ela sabemos de onde vemos nossos acessos, tempo de permanência no site, enfim, o perfil do nosso leitor. Descobrimos, por exemplo, que a maior parte dos nossos visitantes estão em São Paulo, seguido por Rio de Janeiro, Belo Horizonte e Brasília. Temos aí, portanto, um reflexo do mapa de exclusão digital que caracteriza o país.

Além disso, fazemos pesquisas espontâneas para saber mais sobre a formação desse leitor. Essas pesquisas nos revelaram recentemente que entre 70\% e 75\% dos visitantes do Café História são da área de história, enquanto os demais são não-historiadores. Acredito que essa proporção é comum em qualquer projeto de divulgação científica no formato escrito, mas nossa meta é chegar nos próximos três anos a um público de 40\% de não-historiadores. Ou seja, queremos escapar da nossa "bolha". Para isso, estamos elaborando algumas estratégias de comunicação. Leva tempo, mas aos poucos vamos nos tornando mais visível para esse público. A maioria dos acessos vem de pessoas que têm entre 24 e 45 anos de idade, a maioria provenientes das classes B e C. Enfim, são muitos os dados.

No que diz respeito ao impacto acadêmico, nossa surpresa tem sido enorme. É comum que artigos de divulgação científica citem artigos de periódicos científicos. O contrário nem tanto. Porém, descobrimos que os artigos do Café História (artigos de divulgação científica) estão sendo 
citados em muitos artigos publicados em periódicos científicos. Ou seja, a comunidade acadêmica tem lido o conteúdo do Café História, reconhecido o seu valor e o utilizado em suas pesquisas. Além da qualidade dos textos dos nossos colaboradores, acho que o processo editorial do Café História ajuda a compreender esse fenômeno: nosso processo de publicação é rápido. Isso ajuda a divulgar mais rapidamente as pesquisas historiográficas.

Tempo \& Argumento: Quais as perspectivas futuras do portal de divulgação científica do Café História em relação à divulgação científica na área da História?

Bruno Leal Pastor de Carvalho: O Café História é um grande laboratório para experiências práticas em História Pública e divulgação científica. Minha ideia para os próximos anos é usar esse espaço de prática para continuar fomentando o debate teórico e conceitual sobre o lugar da história na divulgação científica. Quero entender ainda outros tipos de divulgação histórica, a história da divulgação de história e as mais variadas manifestações de História Pública.

Eu e a Ana Paula Tavares, subeditora da rede, organizamos em 2019 um livro chamado "História Pública e Divulgação de História"3. Esse livro é um esforço nesse sentido. São seis artigos, três entrevistas e uma introdução que se debruçam sobre projetos que buscam popularizar a história. Em 2020/21, espero dar sequência a essa reflexão; pretendo publicar alguns artigos e lançar um novo livro.

A Universidade de Brasília (UnB) também tem sido um grande espaço para o desenvolvimento de projetos no campo da divulgação científica em história. No final do ano passado, eu e alguns colegas do departamento de história montamos o Núcleo de Difusão de Saberes Históricos, que vai decolar este ano com várias iniciativas bem interessantes. No primeiro semestre de 2020, vou ministrar também uma disciplina intitulada "Divulgação Científica e História Pública" na UnB. É a segunda vez que ministro uma disciplina com essa abordagem - a primeira vez foi em 2017, na UFRJ. Até o momento, a disciplina teve mais de 60 solicitações de matrícula, o que demonstra a demanda no meio acadêmico de tópicos especiais que abordam essas questões. 
Tenho certeza que dessa disciplina nascerão muitas ideias que terão impacto em minhas reflexões teóricas e em minhas práticas enquanto divulgador. 